Celgene, Lilly, Janssen, Novartis, Pfizer, Christopher T. Ritchlin Grant/research support from: UCB Pharma, AbbVie, Amgen, Consultant of: UCB Pharma, Amgen, AbbVie, Lilly, Pfizer, Novartis, Gilead, Janssen, Philip Helliwell: None declared, Wolf-Henning Boehncke Grant/research support from: Janssen Research \& Development, LLC, Consultant of: Janssen, Philip J Mease Grant/ research support from: Abbott, Amgen, Biogen Idec, BMS, Celgene Corporation, Eli Lilly, Novartis, Pfizer, Sun Pharmaceutical, UCB - grant/research support, Consultant of: Abbott, Amgen, Biogen Idec, BMS, Celgene Corporation, Eli Lilly, Novartis, Pfizer, Sun Pharmaceutical, UCB - consultant, Speakers bureau: Abbott, Amgen, Biogen Idec, BMS, Eli Lilly, Genentech, Janssen, Pfizer, UCB speakers bureau, Alice B Gottlieb Grant/research support from:: Research grants, consultation fees, or speaker honoraria for lectures from: Pfizer, AbbVie, BMS, Lilly, MSD, Novartis, Roche, Sanofi, Sandoz, Nordic, Celltrion and UCB., Consultant of:: Research grants, consultation fees, or speaker honoraria for lectures from: Pfizer, AbbVie, BMS, Lilly, MSD, Novartis, Roche, Sanofi, Sandoz, Nordic, Celltrion and UCB., Speakers bureau:: Research grants, consultation fees, or speaker honoraria for lectures from: Pfizer, AbbVie, BMS, Lilly, MSD, Novartis, Roche, Sanofi, Sandoz, Nordic, Celltrion and UCB., Shelly Kafka Employee of: Janssen Scientific Affairs, LLC, Alexa Kollmeier Shareholder of: Johnson \& Johnson, Employee of: Janssen Research \& Development, LLC, Elizabeth C Hsia Shareholder of: Johnson \& Johnson, Employee of: Janssen Research \& Development, LLC, Xie L Xu Shareholder of: Johnson \& Johnson, Employee of: Janssen Research \& Development, LLC, May Shawi Shareholder of: Johnson \& Johnson, Employee of: Janssen Research \& Development, LLC, Shihong Sheng Shareholder of: Johnson \& Johnson, Employee of: Janssen Research \& Development, LLC, Prasheen Agarwal Shareholder of: Johnson \& Johnson, Employee of: Janssen Research \& Development, LLC, Bei Zhou Shareholder of: Johnson \& Johnson, Employee of: Janssen Research \& Development, LLC, Paraneedharan Ramachandran Employee of: Janssen Research \& Development, LLC, lain Mclnnes Grant/research support from: Bristol-Myers Squibb, Celgene, Eli Lilly and Company, Janssen, and UCB, Consultant of: AbbVie, Bristol-Myers Squibb, Celgene, Eli Lilly and Company, Gilead, Janssen, Novartis, Pfizer, and UCB DOI: 10.1136/annrheumdis-2020-eular.387

\section{FRI0360 IMPACT OF METHOTREXATE ON DISEASE PATTERN IN ACTIVE PSORIATIC ARTHRITIS PATIENTS ELIGIBLE FOR A RANDOMIZED CLINICAL TRIAL WITH USTEKINUMAB: COMPARATIVE BASELINE DATA FROM MULTICENTRE INVESTIGATOR-INITIATED MUST TRIAL}

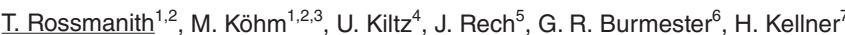
A. Bulczak-Schadendorf ${ }^{1,2}$, A. C. Foldenauer ${ }^{1,2}, H$. Burkhardt ${ }^{1,2,3}$, F. Behrens ${ }^{1,2,3}$ ${ }^{1}$ Fraunhofer IME Translational Medicine and Pharmacology, Frankfurt, Germany; ${ }^{2}$ Fraunhofer Cluster of Excellence Immune-mediated Diseases CIMD, Frankfurt, Germany; ${ }^{3}$ Goethe-University Frankfurt, Rheumatology Department, Frankfurt, Germany; ${ }^{4}$ Rheumazentrum Ruhrgebiet, Herne, Germany; ${ }^{5}$ Universität Erlangen, Rheumatology Department, Erlangen, Germany; ${ }^{6}$ Universitätsmedizin Charité, Department for Rheumatology and Immunology, Berlin, Germany;

${ }^{7}$ Rheumapraxis, München, Germany

Background: Methotrexate (MTX) is a csDMARD treatment that is initiated as first-line therapy (after NSAID) in active psoriatic arthritis (PsA). Randomized clinical trials mostly require treatment failure or intolerance of csDMARD/MTX therapy before initiation of a biological treatment. We designed an investigatorinitiated (IIT) randomised blinded study comparing PsA patients starting open label Ustekinumab (UST) combined with blinded MTX or placebo (PLC). Patients are stratified regarding their previous MTX therapy (continuation or discontinuation of MTX (MTX-pre-treated patients -group A) or newly initiate MTX or continue without MTX (MTX-naïve patients - group B).

Objectives: To determine disease characteristics of patients with active psoriatic arthritis regarding their skin and musculoskeletal manifestations in dependence of their MTX treatment status.

Methods: A total of 186 patients with active PsA (defined as TJC $\geq 4$, SJC $\geq 4$ (68/66 joint count) and DAS28 $\geq 3,2$ ) were screened for eligibility. At baseline (BL) 173 patients starting open label UST were randomised to receive either MTX or PLC. At Screening (SCR) and BL, demographic data, PsA and PsO disease activity (joint count (TJC/SJC), enthesitis (LEI), dactylitis (number of digits), PASI, BSA, mtNAPSI), previous medication as well as quality of life (QoL) and function (documented as PRO using DLQI, HAQ and subjects assessment of pain as visual analogue scale (VAS) was documented.

Results: Our preliminary blinded data export comprised all documented and released data for SCR and BL until Mid-January 2020 - in total 154 randomized patients. Thereof, 78 patients were randomized in group $A$ and 76 in group B. BL characteristics were well balanced between groups (mean age $A: 50,7$ years vs. $46,4$ in B, BMl 29 vs. 29,6 in B). More male were included in B (72\% vs. $50 \%)$. In median, patients in $A$ had a disease duration of $2,9 \mathrm{y}$ whereas duration in $B$ was in median 0,3 y. More patients in A had failed previous biological therapy (17 to 6 in
B), discontinued due to intolerability or ineffectiveness as allowed for study inclusion. Mean DAS28 was 4,5 (moderate disease activity) for both groups and mean values for SGA, PGA were comparable (SGA: 59,1 vs 54,9 PGA: 61,4 vs. 55.6 ) reflecting comparable disease activity in peripheral arthritis. Mean LEI was comparable in both groups (A: 1,3 vs $B: 1,1)$. Mean number of digits with dactylitis were slightly higher in $B(0,8)$ than in $A(0,2)$. Overall $H A Q$ showed no differences (1.0 in $B$ vs. 0.8 in $A$ - missing data 45 and 29 resp.) and pain VAS did not differ between groups (A: $54,9 \mathrm{~mm}$ vs. $56,6 \mathrm{~mm}$ in $\mathrm{B}$ ). PASI and NAPSI were higher in $\mathrm{B}$ at $\mathrm{BL}$ than in group A (PASI: 7,2 vs. 3,3, mtNAPSI 5,0 vs. 3,0) and PRO showed a higher skin disease burden experienced by MTX-naïve patients prior randomization: in DLQ more patients on MTX experience "no effect" of their skin disease on QoL (22\% vs. 7\%) whereas more MTX naïve patients see a "moderate" "large" to "extreme large effect" of their disease on QoL ( $16 \%, 11 \%, 5 \%$ in B vs. $10 \%, 8 \%, 3 \%$ in A).

Conclusion: Our results give important information about comparability of patient population on MTX or without MTX therapy eligible for biological trials. Despite a comparable disease activity in peripheral arthritis scores, skin disease activity was increased in patients without MTX compared to MTX treated patients. Number of affected digits in dactylitis was lower with MTX, whereas its impact on enthesitis seems to be neglectable.

Disclosure of Interests: Tanja Rossmanith Grant/research support from: Janssen, BMS, LEO, Pfizer, Michaela Köhm Grant/research support from: Pfizer, Janssen, BMS, LEO, Consultant of: BMS, Pfizer, Speakers bureau: Pfizer, BMS, Janssen, Novartis, Uta Kiltz Grant/research support from: AbbVie, Amgen, Biogen, Novartis, Pfizer, Consultant of: AbbVie, Biocad, Eli Lilly and Company, Grünenthal, Janssen, Novartis, Pfizer, UCB, Speakers bureau: AbbVie, MSD Novartis, Pfizer, Roche, UCB, Jürgen Rech Consultant of: BMS, Celgene, Novartis, Roche, Chugai, Speakers bureau: AbbVie, Biogen, BMS, Celgene, MSD, Novartis, Roche, Chugai, Pfizer, Lilly, Gerd Rüdiger Burmester Consultant of: AbbVie Inc, Eli Lilly, Gilead, Janssen, Merck, Roche, Pfizer, and UCB Pharma, Speakers bureau: AbbVie Inc, Eli Lilly, Gilead, Janssen, Merck, Roche, Pfizer, and UCB Pharma, Herbert Kellner: None declared, Anita Bulczak-Schadendorf Grant/research support from: Janssen, Ann Christina Foldenauer: None declared, Harald Burkhardt Grant/research support from: Pfizer, Roche, Abbvie, Consultant of: Sanofi, Pfizer, Roche, Abbvie, Boehringer Ingelheim, UCB, Eli Lilly, Chugai, Bristol Myer Scripps, Janssen, and Novartis, Speakers bureau: Sanofi, Pfizer, Roche, Abbvie, Boehringer Ingelheim, UCB, Eli Lilly, Chugai, Bristol Myer Scripps, Janssen, and Novartis, Frank Behrens Grant/research support from: Pfizer, Janssen, Chugai, Celgene, Lilly and Roche, Consultant of: Pfizer, AbbVie, Sanofi, Lilly, Novartis, Genzyme, Boehringer, Janssen, MSD, Celgene, Roche and Chugai DOI: 10.1136/annrheumdis-2020-eular.5511

\section{FRI0361 CARTILAGE DEGRADATION IN PSORIATIC ARTHRITIS IS ASSOCIATED WITH INCREASED SYNOVIAL PERFUSION AS DETECTED BY MAGNETIC RESONANCE IMAGING}

P. Sewerin ${ }^{1}$, D. Abrar ${ }^{2}$, A. Müller-Lutz ${ }^{2}$, M. Frenken², K. L. Radke ${ }^{2}$ S. Vordenbäumen ${ }^{1}$, M. Schneider ${ }^{1}$, B. Ostendorf ${ }^{1}$, C. Schleich ${ }^{2} .{ }^{1}$ Heinrich Heine University, Department for Rheumatology, Duesseldorf, Germany; ${ }^{2}$ Heinrich Heine University, Institute for Diagnostic and Interventional Radiology, Duesseldorf, Germany

Background: Even though cartilage loss is a known feature of psoriatic arthritis (PsA), research is sparse on its role in the pathogenesis of PsA and its potential use for disease detection and monitoring. Using delayed gadolinium-enhanced magnetic resonance imaging of cartilage (dGEMRIC) and dynamic contrast-enhanced MRI (DCE MRI), research has shown that early cartilage loss is strongly associated with synovial inflammation in rheumatoid arthritis (RA). The aim of this study was to determine if acute inflammation is associated with early cartilage loss in small finger joints of patients with PsA.

Objectives: Is local perfusion in PsA patients measured by dynamic MRI associated to local cartilage loss?

Methods: Metacarpophalangeal (MCP), proximal interphalangeal (PIP), and distal interphalangeal (DIP) joints of 17 patients with active PsA were evaluated by high-resolution 3 Tesla dGEMRIC and DCE MRI using a dedicated 16-channe hand coil. Semi-quantitative and quantitative perfusion parameters were calculated. Images were analyzed by two independent raters for dGEMRIC indices, PsA MR scores (PsAMRIS), total cartilage thickness (TCT), and joint space width (JSW). Results: We found significant negative correlations between perfusion parameters (except $\mathrm{K}_{\mathrm{ep}}$ ) and dGEMRIC indices, with the highest value at the MCP joints $\left(\mathrm{K}_{\mathrm{Tran}}\right.$ : $\tau=-0.54, p=0.01 ; K_{e p}: \tau=-0.02, p=0.90 ;$ IAUC: $\tau=-0.51, p=0.015$; Initial Slope: $\tau=$ $-0.54, p=0.01$; Peak: $\tau=-0.67, p=0.002)$. Heterogeneous correlations were detected between perfusion parameters and both, total PsAMRIS and PsAMRIS synovitis sub-scores. No significant correlation was seen between any perfusion parameter and JSW and/or TCT.

Conclusion: As examined by DCE MRI and dGEMRIC, there is a significant association between early cartilage loss and acute synovial inflammation in small finger joints of PsA patients. 

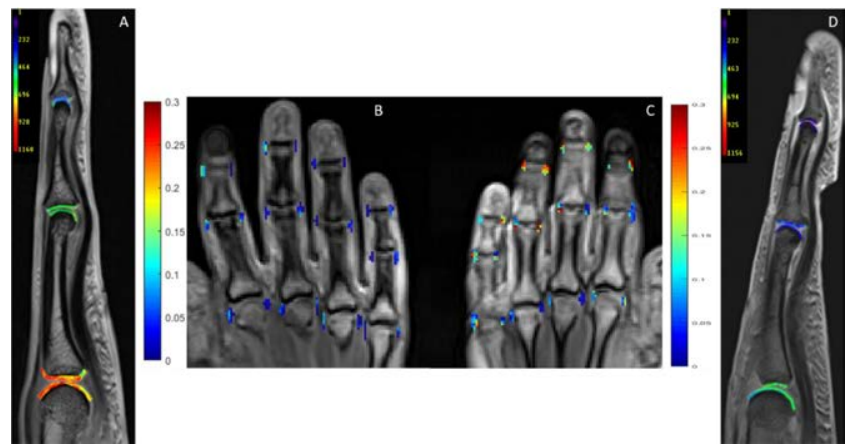

Figure 1. dGEMRIC maps (third digit) and perfusion maps (peak parameter) of MCP, PIP, and DIP joints in 26-year-old male ( $A$ and $B$ ) and a 59-year-old female ( $C$ and $D)$ with PsA. Lower dGEMRIC values are illustrated in D, indicating more proteoglycan loss than in A. Higher peak values are depicted in $\mathrm{C}$, indicating a higher severity of synovitis than in $\mathrm{B}$. Peak parameter is illustrated in $\mathrm{mM} / \mathrm{l}$ per second, dGEMRIC indices in $\mathrm{ms}$.

Disclosure of Interests: Philipp Sewerin Grant/research support from: AbbVie Deutschland $\mathrm{GmbH}$ \& Co. KG

Bristol-Myers Squibb Celgene $\mathrm{GmbH}$

Lilly Deutschland $\mathrm{GmbH}$

Novartis Pharma GmbH Pfizer Deutschland GmbH

Rheumazentrum Rhein-Ruhr, Consultant of: AMGEN GmbH AbbVie Deutschland $\mathrm{GmbH}$ \& Co. KG Biogen GmbHBristol-Myers Squibb Celgene GmbH Chugai Pharma arketing Ltd. / Chugai Europe GmbHHexal Pharma Janssen-CilagGmbH Johnson \& Johnson Deutschland GmbHLilly Deutschland GmbH / Lilly Europe / Lilly Global Novartis Pharma GmbH Pfizer Deutschland GmbH Roche Pharma Rheumazentrum Rhein-Ruhr Sanofi-Genzyme Deutschland GmbH Swedish Orphan Biovitrum GmbH UCB Pharma GmbH, Speakers bureau: AMGEN GmbH AbbVie Deutschland GmbH \& Co. KG Biogen GmbHBristol-Myers Squibb Celgene GmbH Chugai Pharma arketing Ltd. / Chugai Europe GmbHHexal Pharma Janssen-CilagGmbH Johnson \& Johnson Deutschland GmbHLilly Deutschland GmbH / Lilly Europe / Lilly Global Novartis Pharma GmbH Pfizer Deutschland $\mathrm{GmbH}$ Roche Pharma Rheumazentrum Rhein-Ruhr Sanofi-Genzyme Deutschland $\mathrm{GmbH}$ Swedish Orphan Biovitrum GmbH UCB Pharma $\mathrm{GmbH}$, Daniel Abrar: None declared, Anja Müller-Lutz: None declared, Miriam Frenken: None declared, Karl Ludger Radke: None declared, Stefan Vordenbäumen: None declared, Matthias Schneider Grant/research support from: GSK, UCB, Abbvie, Consultant of: Abbvie, Alexion, Astra Zeneca, BMS, Boehringer Ingelheim, Gilead, Lilly, Sanofi, UCB, Speakers bureau: Abbvie, Astra Zeneca, BMS, Chugai, GSK, Lilly, Pfizer, Sanofi, Benedikt Ostendorf: None declared, Christoph Schleich: None declared

DOI: 10.1136/annrheumdis-2020-eular.6314

\section{FRI0362 COMPARATIVE EFFECTIVENESS OF USTEKINUMAB (UST) AND TNF INHIBITORS (TNFI) IN PATIENTS WITH PSORIATIC ARTHRITIS (PSA) IN THE REAL- WORLD, MULTINATIONAL PSABIO STUDY: 12-MONTH FOLLOW-UP}

J. S. Smolen ${ }^{1}$, S. Siebert ${ }^{2}$, T. Korotaeva ${ }^{3}$, P. Bergmans ${ }^{4}$, K. De Vlam ${ }^{5}$, E. Gremese ${ }^{6}$, B. Joven-lbáñez ${ }^{7}$, W. Noel ${ }^{8}$, M. T. Nurmohamed ${ }^{9}$, P. Sfikakis ${ }^{10}$, E. Theander ${ }^{11}$, L. Gossec ${ }^{12} .{ }^{1}$ Medical University of Vienna, Vienna, Austria; ${ }^{2}$ University of Glasgow, Glasgow, United Kingdom; ${ }^{3}$ Nasonova Research Institute of Rheumatology, Moscow, Russian Federation; ${ }^{4}$ Janssen, Breda, Netherlands; ${ }^{5}$ University Hospitals, Leuven, Belgium; ${ }^{6}$ Catholic University of the Sacred Heart, Fondazione Policlinico Gemelli - IRCCS, Rome, Italy; ${ }^{7} \mathrm{Hospital}$ 12 de Octubre, Madrid, Spain; ${ }^{8}$ Janssen, Brussels, Belgium; ${ }^{9}$ VU University Medical Centre \& Reade, Amsterdam, Netherlands; ${ }^{10}$ University of Athens Medical School, Athens, Greece; ${ }^{11}$ Janssen, Solna, Sweden; ${ }^{12}$ Sorbonne University, Paris, France

Background: Among treatment options for PsA, IL-12/23 inhibition with UST was the first new biologic mode of action after TNFi. Few real-world data comparing UST with TNFi are available.

Objectives: Comparison of UST and TNFi treatment effectiveness within the prospectively followed PsABio cohort at 12-month (mo) follow-up.

Methods: The PsABio study (NCT02627768) evaluates effectiveness, tolerability and persistence of 1st, 2nd or 3rd-line UST or TNFi in PsA. Proportions of patients (pts) reaching MDA/very low disease activity (VLDA) and clinical Disease Activity index for PSoriatic Arthritis (cDAPSA) LDA/remission are described. Comparison across UST and TNFi cohorts was done on last observation carried forward up to $12( \pm 3)$ mo, with non-response imputation for pts who had stopped/switched initial treatment. Logistic regression analysis was used, including propensity score (PS) analysis to adjust for imbalanced prognostic baseline $(\mathrm{BL})$ covariates: country, age, sex, BMI, smoking (yes/no), comorbidities (cardiovascular/metabolic syndrome), PsA type (axial, polyarticular, oligoarticular), psoriasis body surface area (BSA), disease duration, cDAPSA, 12-item PsA Impact of Disease (PsAID-12), dactylitis, enthesitis, Fibromyalgia Rapid Screening Tool (FiRST) score, line of biologic (b)DMARD, synthetic DMARD use, and steroid or NSAID use.

Results: Of 929 eligible pts, 893 had evaluable data at BL and at follow-up; $438(95.6 \%)$ were treated with UST and 455 (96.6\%) with TNFi (including stoppers/switchers). UST and TNFi groups had BL differences in mean age (51.0 vs 48.5 years, respectively), concurrent comorbidities ( $68.7 \%$ vs $60.9 \%)$, time since diagnosis (7.5 vs 6.2 years), line of treatment (1st-line $45.0 \%$ vs $55.2 \%$; 3rd-line $20.5 \%$ vs $12.1 \%$ ), NSAID use ( $54.8 \%$ vs $68.8 \%)$, concomitant MTX use $(29.9 \%$ vs $42.0 \%$ ) and psoriasis skin involvement (BSA $>10 \%$ in $26.6 \%$ vs $14.8 \%$ ). In 714 pts with available data, mean (standard deviation) BL CDAPSA was 30.6 (20.2; $n=358)$ for UST and $29.3(18.6 ; n=356)$ for TNFi. Observed data showed differences in proportion of pts achieving MDA/VLDA and cDAPSA LDA/remission in favour of TNFi, but after PS adjustment for BL differences (such as line of therapy, skin psoriasis, concomitant conventional DMARD, etc.), odds ratios for reaching targets at 12 mo did not significantly differ between UST and TNFi groups (Fig. 1)

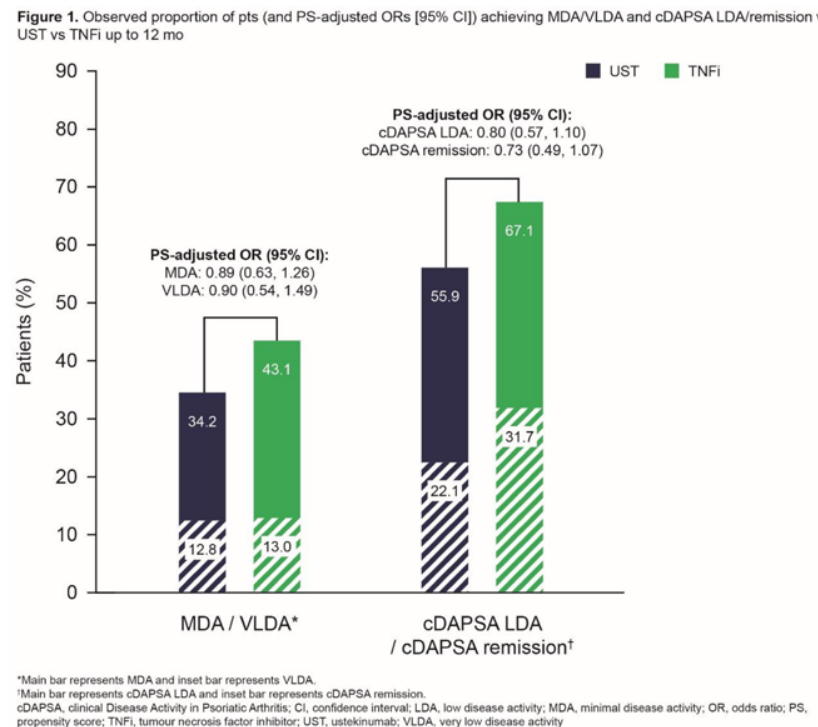

Comparison of 6- and 12-mo unadjusted data showed sustained MDA/VLDA responses with both UST $(21.8 \%)$ and TNFi $(29.5 \%)$, with comparable proportions of additional pts achieving these targets between 6 and $12 \mathrm{mo}(17.0 \%$ and $20.3 \%$, respectively). Sustained efficacy became lower with successive lines of treatment (data not shown)

Conclusion: Various factors, including patient characteristics such as comorbidities, influence the physician's selection of treatment modality for patients needing a bDMARD. Our real-world results demonstrate differences in observed clinical effectiveness between UST and TNFi. However, after PS adjustment for a number of $\mathrm{BL}$ differences, clinical results at 12 mo were comparable between UST and TNFi groups. Data at 12 mo also show sustained response with both UST and TNFi treatment, as well as a similar rate of pts achieving targets after 6 to 12 mo of treatment.

Acknowledgments: This study was funded by Janssen.

Disclosure of Interests: Josef S. Smolen Grant/research support from: AbbVie, AstraZeneca, Celgene, Celltrion, Chugai, Eli Lilly, Gilead, ILTOO, Janssen, Novartis-Sandoz, Pfizer Inc, Samsung, Sanofi, Consultant of: AbbVie, AstraZeneca, Celgene, Celltrion, Chugai, Eli Lilly, Gilead, ILTOO, Janssen, Novartis-Sandoz, Pfizer Inc, Samsung, Sanofi, Stefan Siebert Grant/research support from: BMS, Boehringer Ingelheim, Celgene, GlaxoSmithKline, Janssen, Novartis, Pfizer, UCB, Consultant of: AbbVie, Boehringer Ingelheim, Janssen, Novartis, Pfizer UCB, Speakers bureau: AbbVie, Celgene, Janssen, Novartis, Tatiana Korotaeva Grant/research support from: Pfizer, Consultant of: Abbvie, BIOCAD, Bristol-Myers Squibb, Celgene, Eli Lilly, Janssen, Merck Sharp \& Dohme, Novartis, Novartis-Sandoz, Pfizer, UCB, Speakers bureau: Abbvie, BIOCAD, Bristol-Myers Squibb, Celgene, Eli Lilly, Janssen, Merck Sharp \& Dohme, Novartis, Novartis-Sandoz, Pfizer, UCB, Paul Bergmans Shareholder of: Johnson \& Johnson, Employee of: Janssen, Kurt de Vlam Consultant of: Celgene Corporation, Eli Lilly, Novartis, Pfizer, UCB - consultant, Speakers bureau: Celgene Corporation, Eli Lilly, Novar tis, Pfizer, UCB - speakers bureau and honoraria, Elisa Gremese Consultant of: AbbVie, Bristol-Myers Squibb, Celgene, Eli Lilly, Janssen, Merck Sharp \& Dohme, Novartis, Sanofi, UCB, Roche, Pfizer, Speakers bureau: AbbVie, Bristol-Myers 